\title{
Aloe-emodin inhibits the proliferation, migration, and invasion of melanoma cells via inactivation of the Wnt/beta-catenin signaling pathway
}

\author{
Maotao Du ${ }^{1,2}$, Pan Shen ${ }^{1}$, Ranjing $\operatorname{Tan}^{2}$, Dengyan $\mathrm{Wu}^{2}$, Shenghao Tu${ }^{1}$ \\ ${ }^{1}$ Department of Integrated Chinese Traditional and Western Medicine, Tongji Hospital, Tongji Medical College, Huazhong University of Science \\ and Technology, Wuhan, China; ${ }^{2}$ Department of Dermatology and Plastic Surgery, the Second Affiliated Hospital of Chongqing Medical University, \\ Chongqing, China \\ Contributions: (I) Conception and design: M Du; (II) Administrative support: M Du, P Shen; (III) Provision of study materials or patients: R Tan, D \\ Wu; (IV) Collection and assembly of data: M Du, P Shen, R Tan, D Wu; (V) Data analysis and interpretation: M Du, P Shen, R Tan, D Wu; (VI) \\ Manuscript writing: All authors; (VII) Final approval of manuscript: All authors. \\ Correspondence to: Shenghao Tu. Department of Integrated Chinese Traditional and Western Medicine, Tongji Hospital, Tongji Medical College, \\ Huazhong University of Science and Technology, Jiefang Avenue 1095, Wuhan 430030, China. Email: bslw2017@sina.com.
}

\begin{abstract}
Background: Aloe-emodin is reported as a potential cancer therapeutic agent due to its inhibition of the proliferation, migration, and invasion of cancer cells. This study aimed to confirm the effects of aloe-emodin on the progression of melanoma and identify the underlying molecular mechanisms.

Methods: The effects of aloe-emodin treatment (concentrations ranging from 0 to $25 \mu \mathrm{g}, 48 \mathrm{~h}$ ) on proliferation, apoptosis, distribution of cell cycle, migration, and invasion were detected by performing Cell Counting Kit-8 (CCK-8) assay, colony formation assay, flow cytometry, wound healing assay, and Transwell invasion experiments. Rescue experiments were carried out by overexpression of $\beta$-catenin to verify the role of $\beta$-catenin in the inhibition of melanoma by aloe-emodin. The analysis was carried out at the animal level by constructing tumor-bearing nude mice model.

Results: The results showed that aloe-emodin prominently reduced the proliferation, migration, and invasion of melanoma cells. Additionally, it was found that aloe-emodin significantly enhanced the cell apoptosis and induced G2 phase arrest of melanoma cells via enhancing the expressions of cleaved-caspase3, bax, and reducing cyclinD1, c-myc, and bcl-2. In addition, aloe-emodin could also inhibit Wnt3a levels, and promote GSK3-beta and beta-catenin phosphorylation. In vivo experiments also showed that overexpression of beta-catenin reversed the effects of aloe-emodin on tumor growth.

Conclusions: In conclusion, our findings indicated that aloe-emodin might prominently inhibit the tumor growth and metastasis of melanoma via the Wnt/beta-catenin signaling pathway in vitro. Therefore, aloeemodin may serve as a potential drug for the clinical treatment of melanoma.
\end{abstract}

Keywords: Melanoma; aloe-emodin; Wnt/beta-catenin

Submitted Aug 19, 2021. Accepted for publication Nov 18, 2021.

doi: $10.21037 / \mathrm{atm}-21-5437$

View this article at: https://dx.doi.org/10.21037/atm-21-5437

\section{Introduction}

Melanoma is a fatal malignancy with increasing incidence worldwide, and is the leading cause of skin cancer-related death $(1,2)$. Multiple studies have indicated that melanoma is caused by the dysregulation of oncogenic and tumor suppressor pathways including the MAPK, PI3K/AKT, and $\mathrm{Wnt} /$ beta-catenin signaling pathways (3-5). The Wnt signaling plays a crucial role in regulating development in the embryonic stage and maintaining tissue homeostasis in adults. Ectopic activation of Wnt signaling contributes to 
tumorigenesis and tumor promotion by enhancing cancer cell proliferation, viability, and drug-resistance (6). In the A375 melanoma cell lines, down-regulating or inhibiting the activity of beta-catenin might reduce the proliferation, migration, and invasion of cells, and then accelerate cell apoptosis (7). Moreover, it has been demonstrated that the Wnt signaling pathway plays a crucial role in age-related poor outcomes of melanoma (8). It has also been confirmed that regulating the activation level of the Wnt pathway is an effective target for treating melanoma $(3,9,10)$. Although inhibition of the Wnt pathway currently plays an important role in the treatment of melanoma, how to regulate the Wnt pathway is still the focus of research.

Some natural substances present in plants have antitumor activity. Aloe-emodin is a kind of anthraquinone extracted from aloe, the chemical formula is $\mathrm{C}_{15} \mathrm{H}_{10} \mathrm{O}_{5}$, which has been used as a traditional Chinese medicine for centuries (11). A number of beneficial biochemical properties of aloeemodin have been found, including anti-inflammatory, immunoregulation, and promotion of wound healing (12). At present, emerging evidence has demonstrated that aloeemodin exhibits anti-carcinogenic capacity in a variety of cancers by inhibiting cell proliferation, migration, and invasion (13). For example, aloe-emodin can suppress the proliferation of cervical cancer cell lines, Hela and $\mathrm{SiHa}$ cells, via the inhibition of glucose metabolism by decreasing the expression of glucose transporter-1 (GLUT1) (14). Similarly, aloe-emodin exerted anti-tumor effects on hepatocellular carcinoma cells by inhibiting cell proliferation and inducing cell apoptosis through reducing the expression levels of calpain-2 and ubiquitin-protein ligase $\mathrm{E} 3 \mathrm{~A}$, and then activating an apoptosis signaling pathway (15). Two recent studies have found that aloeemodin may have anti-melanoma activity $(16,17)$. The results shows that aloe-emodin inhibits metastasis of B16-F10 cells in vitro. However, the effect of aloe-emodin on the biological behavior of melanoma cells in vitro and in vivo is not clear, and the mechanism of action of aloeemodin in melanoma needs to be explored.

In the present study, we demonstrated the anti-cancer properties of aloe-emodin in melanoma. Moreover, our further experiments identified the role of the Wnt signaling pathway in the inhibition of tumor growth of melanoma caused by treatment with aloe-emodin, proving that aloe-emodin may be a potential anti-cancer drug for the treatment of melanoma.

We present the following article in accordance with the
ARRIVE reporting checklist (available at https://dx.doi. org/10.21037/atm-21-5437).

\section{Methods}

\section{Cell culture}

A375 and SK-MEL-28 cells were purchased from the Chinese Academy of Sciences Cell Bank. The cells were cultured in DMEM medium (Thermo Fisher Scientific, Waltham, MA, USA) with $10 \%$ fetal bovine serum (FBS; Gibco, NY, USA) and $1 \%$ penicillin-streptomycin liquid (Solarbio, Beijing, China) at $37{ }^{\circ} \mathrm{C}, 5 \% \mathrm{CO}_{2}$ incubator.

\section{Cell Counting Kit-8 (CCK-8) assay}

A $100 \mu \mathrm{L}$ cell suspension at a concentration of $5 \times 10^{4}$ cells $/ \mathrm{mL}$ was added into 96 -well plates and cultured for 48 h. Next, $10 \mu \mathrm{L}$ CCK-8 (APExBIO, TX, USA) was added into each well and after $2 \mathrm{~h}$ incubation in $37{ }^{\circ} \mathrm{C}$ incubator, the absorbance was examined using a plate reader (model 680; Bio-Rad, Hertfordshire, UK) at $450 \mathrm{~nm}$.

\section{Colony formation assay}

A375 and SK-MEL-28 cells were suspended in DMEM with $10 \% \mathrm{FBS}$ at a density of 100 cells $/ \mathrm{mL}$. After culturing for 2 weeks, the cells were fixed with $4 \%$ paraformaldehyde (PFA) (Sigma, NY, USA) and stained with crystal violet.

\section{Wound healing assay}

A357 and SK-MEL-28 cells were seeded in six-well plates at a concentration of $5 \times 10^{5}$ cells/well. After $48 \mathrm{~h}$ of incubation, wounds were scraped with pipettes. The width of the wound was captured at 0 and $24 \mathrm{~h}$ using a DM2500 bright field microscope (LEICA, Wetazlar, Germany), and the Image (National Institutes of Health, USA) was applied to measure the migration.

\section{Transwell invasion experiment}

A379 and SK-MEL-28 cells were cultured in DMEM and seeded in the upper chambers of a transwell assay, which were coated with matrigel at the concentration of $5 \times 10^{4}$ cells $/ \mathrm{mL}$. The bottom chamber was filled with DMEM with $20 \%$ FBS. After 48 h of incubation, the 
invasive cells were fixed with 4\% PFA (Sigma) and stained with crystal violet.

\section{Cell apoptosis assay}

The cells were washed with $0.01 \mathrm{~mol} / \mathrm{L}$ phosphate-buffered saline (PBS) and suspended in $100 \mu \mathrm{L}$ of binding buffer. Next, $5 \mu \mathrm{L}$ of Annexin V-FITC and $10 \mu \mathrm{L}$ PI was added into the suspension and incubated in the dark for 10-15 minutes at room temperature. Finally, $400 \mu \mathrm{L}$ of $0.01 \mathrm{~mol} / \mathrm{L}$ binding buffer was added into the sample, and the sample was detected by flow cytometry (Becton, NY, USA) within $1 \mathrm{~h}$.

\section{Flow cytometric analysis of cell cycle distribution}

The cells were collected and washed with $0.01 \mathrm{~mol} / \mathrm{L}$ PBS three times, and subsequently fixed with $70 \%$ ethanol at $4{ }^{\circ} \mathrm{C}$ for $4 \mathrm{~h}$. Next, $100 \mu \mathrm{L}$ of binding buffer and $10 \mu \mathrm{L}$ of PI was added, and the suspension was incubated at $4{ }^{\circ} \mathrm{C}$ in the dark for $30 \mathrm{~min}$. Lastly, the sample was tested with flow cytometry (Becton).

\section{Western blot}

The cells were collected and lysed using RIPA buffer (Beyotime, Shanghai, China) with a protease inhibitor cocktail (APExBIO, TX, USA) on ice for $20 \mathrm{~min}$. Next, the suspension was centrifuged at $14,000 \mathrm{rpm}$ at $4{ }^{\circ} \mathrm{C}$ for $20 \mathrm{~min}$. The supernatant was transferred into new microcentrifuge tubes (Eppendorf, Hamburg, Germany) and the protein concentration was detected using a BCA protein assay kit (Thermo Fisher scientific, CA, USA). Twenty $\mu \mathrm{g}$ of each sample was used for SDS-PAGE. The following primary antibodies were used: E-cadherin (Abcam, Cambridge, MA, USA, ab194982) Vimentin (Abcam, ab193555), N-cadherin (Abcam, ab202030), cyclinD1 (Millipore, Billerica, MA, USA, ABE52), cleaved-casepase3 (Millipore, PC679), bax (Millipore, MAB4601), bcl-2 (Abcam, ab185002), and c-myc (Abcam, ab190026).

\section{Reverse real-time quantitative PCR (qRT-PCR)}

The extraction of total RNA was performed using Trizol regent (Thermo Fisher scientific, CA, USA) and the RNA concentration was detected with Nanodrop 2000 (Thermo Fisher Scientific, Waltham, MA, USA). Reverse transcription of $2 \mu \mathrm{g}$ RNA was performed using a high capacity cDNA
Reverse Transcription Kit (Applied Biosystems, Foster City, CA, USA), and real-time quantitative PCR was conducted by using TaqMan Universal Master Mix II. GAPDH was used as the internal reference. Primers: Wnt3a-forward: 5'-TCCCTGGAGCTAGTGTCTCCT-3', Wnt3a-reverse: 5'-GTCAGGTGGGTGGTCAAACC-3'; beta-cateninforward: 5'-TGCAATTTGTGCTCTGCGTC-3', betacatenin-reverse: 5'-TCTTTGTCTTGCGCCACGTC-3'; GAPDH-forward: 5'-CCACCCCCAATGTCTCTGTT-3', GAPDH-reverse: 5'-ATGGATGAACGGCAATCCCC-3'.

\section{Animal study}

In total, 18 male BALB/C nude mice (4 weeks old, 12-16 g) were purchased from Shanghai Slac Laboratory Animal Company (Shanghai, China). The animals were kept in a professional laboratory for nude mice in an atmosphere of $24 \pm 1{ }^{\circ} \mathrm{C}$ with $60 \% \pm 5 \%$ relative humidity. All animals were raised in the same place at the same time by the same experimenter. The mice were randomly divided into three groups: an overexpression-negative control (OE-NC) group, an aloe-emodin $(50 \mathrm{mg} / \mathrm{kg})+$ OE-NC group, and an aloeemodin $(50 \mathrm{mg} / \mathrm{kg})+$ OE-beta-catenin group, with each group consisting of six nude mice. A375 and SK-MEL-28 cells transfected with $\mathrm{OE}-\mathrm{NC}$ and $\mathrm{OE}-$ beta-catenin were suspended with PBS at the density of $5 \times 10^{6}$ cells, and a $100 \mu \mathrm{L}$ suspension was injected subcutaneously into the left armpit area of the mice. After 21 days, the nude mice were sacrificed and the weight of the tumors was evaluated. The examiner did not know the source and grouping of the sample. Care was taken to minimize the pain of the mice. No deaths occurred during the experiment. A protocol was prepared before the study without registration. Experiments were granted by the ethical committee of Huazhong University of Science and Technology (WH201904068), in compliance with Guide for the Care and Use of Laboratory Animals, 8th edition for the care and use of animals.

\section{Statistical analysis}

Each measurement was obtained in three parallel tests. All experimental data were presented as the mean \pm SD . Statistical analyses were performed using GraphPad Prism 7 (GraphPadSoftware, USA) with one-way analysis of variance followed by the Tukey's test for multiple groups and Student's $t$-test for two groups. A P value $<0.05$ was considered statistically significant. 

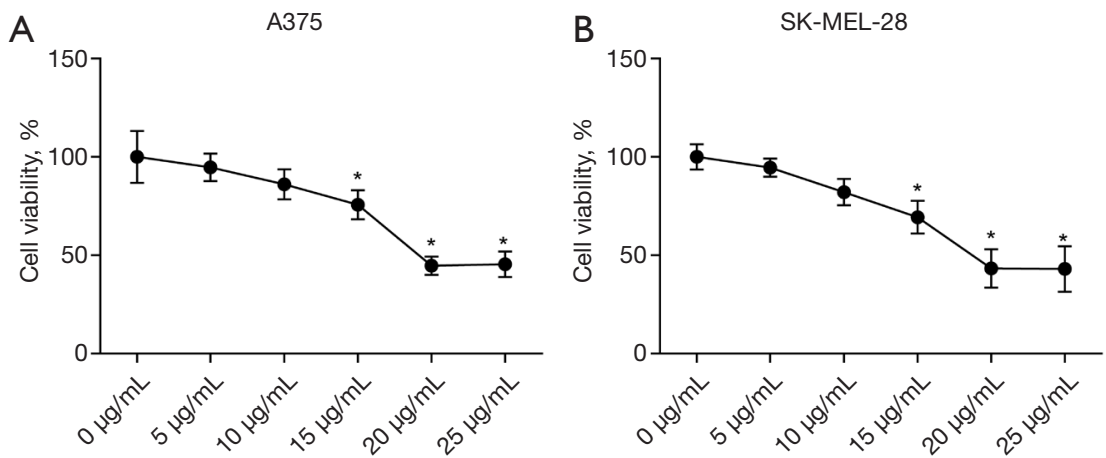

Figure 1 Treatment with aloe-emodin inhibited the cell viability of A375 and SK-MEL-28 cells. (A) Cell viability of A375 cells was detected after aloe-emodin treatment at concentrations of $0,5,10,15,20$, and $25 \mu \mathrm{g} / \mathrm{mL}$; (B) cell viability of SK-MEL-28 cells was determined after aloe-emodin treatment at concentrations of $0,5,10,15,20$, and $25 \mu \mathrm{g} / \mathrm{mL}$. *, $\mathrm{P}<0.05$.

\section{Results}

Aloe-emodin dose-dependently inbibited cell viability of A375 and SK-MEL-28 cells

To investigate the effect of aloe-emodin on the viability of melanoma cells, aloe-emodin (concentrations ranging from 0 to $25 \mu \mathrm{g}$ ) was used to treat A375 and SK-MEL-28 cells. We found that aloe-emodin treatment dose-dependently inhibited the cell viability of A375 and SK-MEL-28 cells (Figure 1A,1B).

\section{The regulatory function of aloe-emodin on the proliferation and survival of A375 and SK-MEL-28 cells}

To confirm the anti-cancer effect of aloe-emodin on melanoma, a CCK-8 assay was applied to examine the function of aloe-emodin on the cell growth of A375 and SKMEL-28 cells treated with aloe-emodin at a concentration of $20 \mu \mathrm{g} / \mathrm{mL}$. The results revealed that aloe-emodin significantly inhibited the proliferative capacity of A375 and SK-MEL-28 cells (Figure 2A,2B). Similarly, the colony formation assay results confirmed the inhibitory function of aloe-emodin on the cell growth of A375 and SK-MEL-28 cells (Figure 2C,2D). G2 phase arrest occurred in A375 and SK-MEL-28 cells following treatment with aloe-emodin (Figure 2E,2F) and the cell apoptosis detected by the FITCAnnexin V/7AAD assay was obviously enhanced after aloeemodin treatment (Figure 2G,2H). Western blot analysis showed a significant enhancement in cleaved-casepase 3 and bax, and reduction in cyclinD1, c-myc, and bcl-2 expression levels in response to aloe-emodin treatment (Figure 2I).

\section{Treatment with aloe-emodin inhibited the migration and invasion of A375 and SK-MEL-28 cells}

We then conducted wound healing and Transwell invasion experiment assays to determine the migration and invasion of A375 and SK-MEL-28 cells after treatment with aloe-emodin. Aloe-emodin led to a marked reduction of migration and invasion of A375 and SK-MEL-28 cells (Figure 3A-3D). Epithelial-mesenchymal transition (EMT) was thought to be responsible for cancer metastasis, and therefore, western blot analysis was used to detect the levels of EMT markers. The results showed that treatment with aloe-emodin prominently decreased the expression level of ICAM and Vimentin, and increased the level of E-cadherin (Figure 3E,3F).

\section{Aloe-emodin affected A375 and SK-MEL-28 cell growth via inactivation of the Wnt/beta-catenin signaling patbway}

To explore the mechanism by which aloe-emodin inhibited the proliferation, migration, and invasion of A375 and SKMEL-28 cells, qRT-PCR and Western blot were adopted to examine the expression of the key protein of the Wnt/betacatenin signaling pathway. As indicated in Figure $4 A-4 D$, the relative mRNA levels of Wnt3a and beta-catenin in A375 and SK-MEL-28 cells after aloe-emodin treatment was significantly down-regulated. Moreover, aloe-emodin inhibited the expression of Wnt3a and p-GSK3beta proteins, and promoted the phosphorylation level of betacatenin protein. 


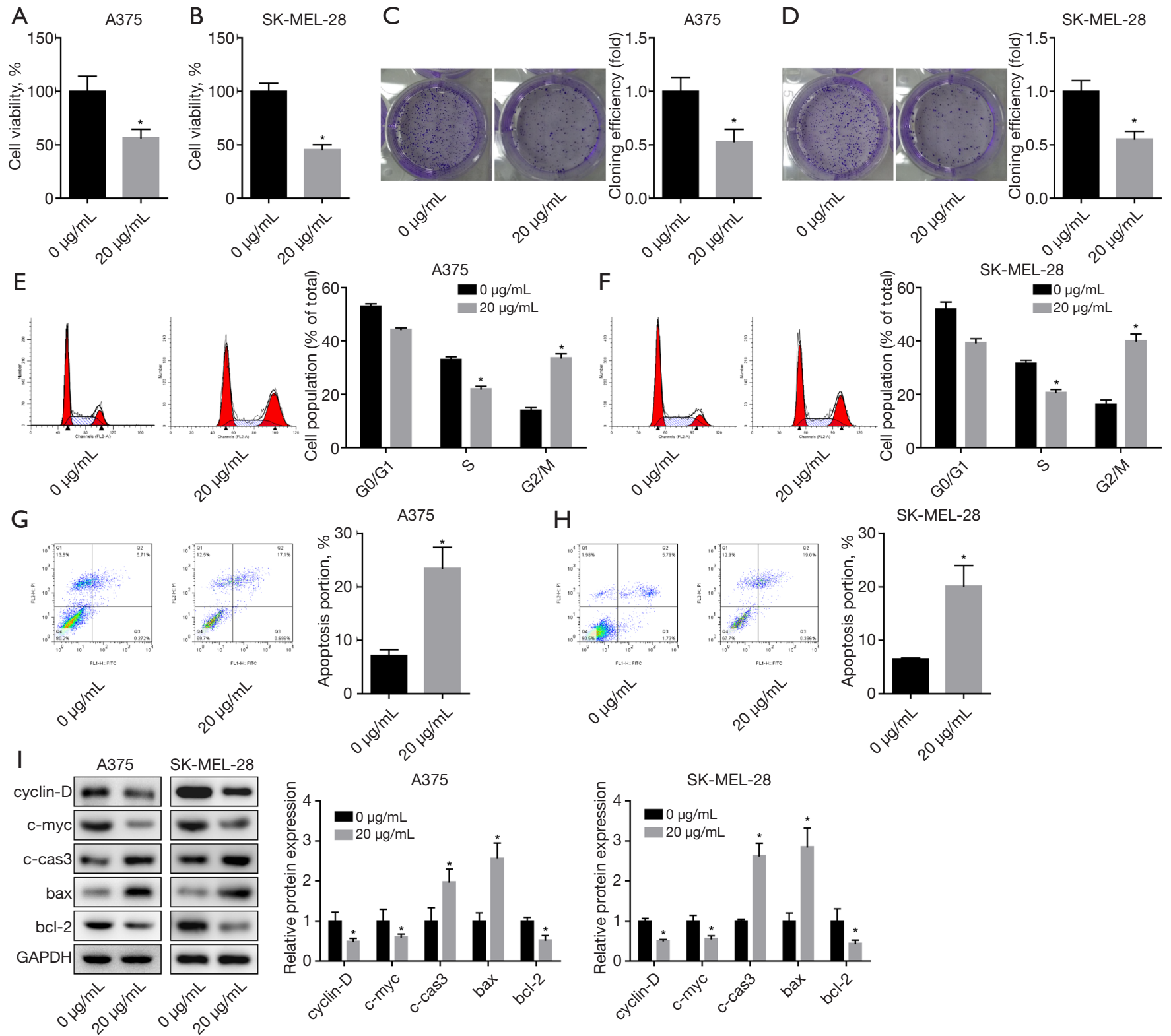

Figure 2 Aloe-emodin inhibited proliferation and induced apoptosis of melanoma cells. (A,B) Cell viability of A375 and SK-MEL-28 cells after aloe-emodin treatment at concentrations of 0 and $20 \mu \mathrm{g} / \mathrm{mL}$; (C,D) image of colony formation and monoclonal quantification, crystal violet was used for cell staining; (E,F) flow cytometry analysis of the cell cycle status of A375 and SK-MEL-28 cells, and the percentage in each phase; (G,H) flow cytometry analysis of the cell state and percentage of cell apoptosis; (I) western blot revealed enhanced expression of cleaved-caspase3 and bax, and reduced expression of cyclinD1, c-myc, and bcl-2 in A375 and SK-MEL-28 cells after treatment with aloeemodin. *, $\mathrm{P}<0.05$.

\section{Overexpression of beta-catenin reversed the effect of aloe- emodin on A375 and SK-MEL-28 cells}

The efficiency of overexpression of beta-catenin in A375 and SK-MEL-28 cells was evaluated with western blot
(Figure $5 A, 5 B$ ). A CCK-8 assay was performed to determine the proliferative ability of A375 and SK-MEL-28 cells after treatment with aloe-emodin and OE-beta-catenin. We found that that OE-beta-catenin abolished the aloeemodin-induced inhibition of cell viability (Figure 5C,5D). 
A
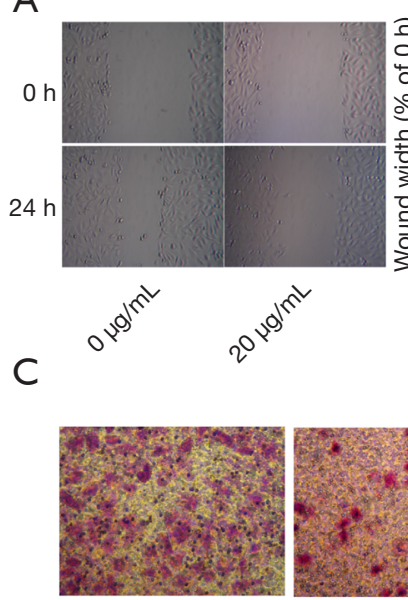

0200

E

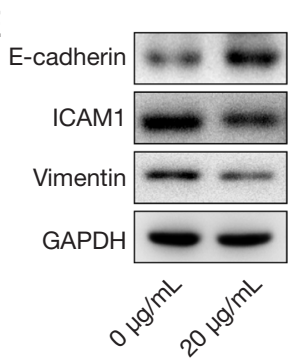

A375

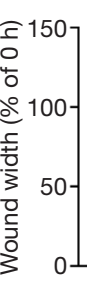

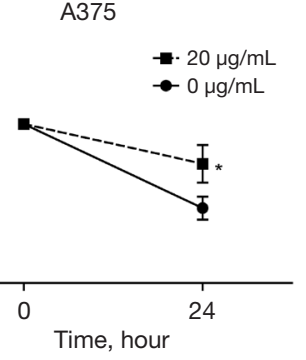

A375

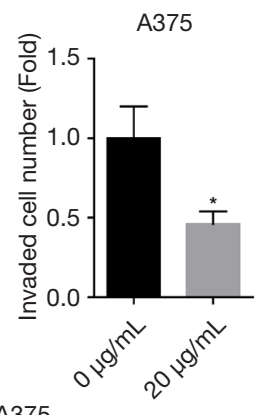

A375

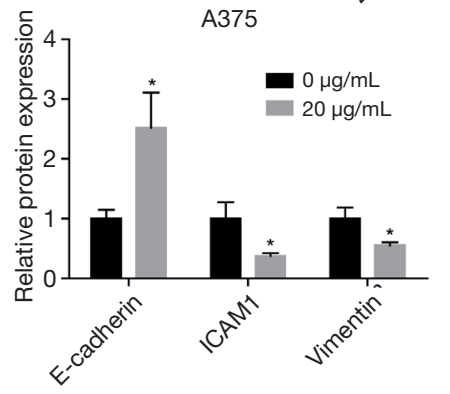

B
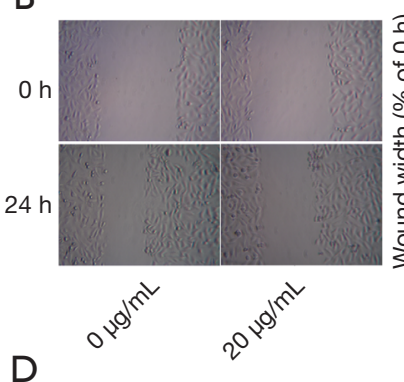

D

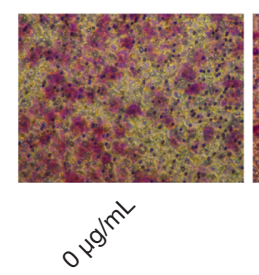

$\mathrm{F}$

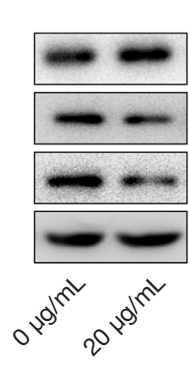

SK-MEL-28

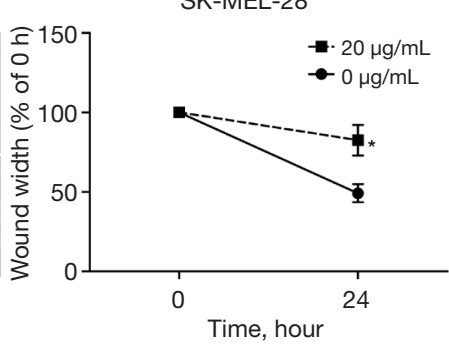

SK-MEL-28

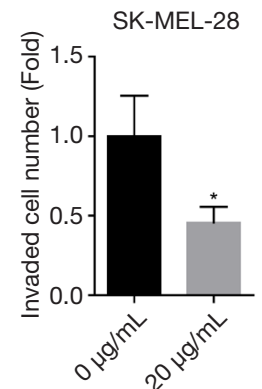

SK-MEL-28

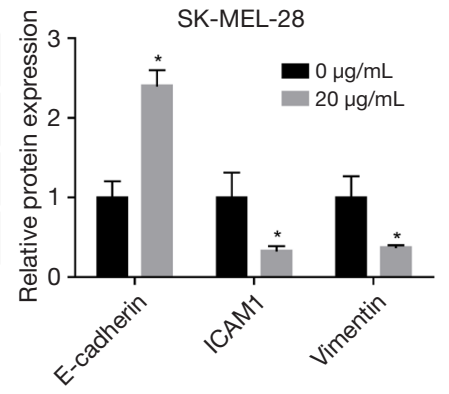

Figure 3 Aloe-emodin inhibited the cell migration and invasion of A375 and SK-MEL-28 cells. (A,B) Wound healing assay and quantification of the migration distance of A375 and SK-MEL-28 cells; (C,D) Transwell invasion experiments and quantification of the invasion of A375 and SK-MEL-28 cells, crystal violet was used for cell staining ( $\times 400)$; (E,F) Western blot showed increased expressions of ICAM1 and Vimentin, and inhibited expression of E-cadherin. *, $\mathrm{P}<0.05$.

In addition, the apoptosis of A375 and SK-MEL-28 cells, which was accelerated by aloe-emodin, was abrogated by OE-beta-catenin (Figure 5E, $5 F$ ). The wound healing assay and Transwell invasion experiment showed that OE-betacatenin abolished the aloe-emodin-induced inhibition of migration and invasion (Figure 5G-57).

\section{Aloe-emodin inbibited the tumor growth of melanoma in vivo}

To detect the effect of aloe-emodin on the tumor growth of melanoma in vivo, a nude mouse model of transplant tumor was used. As shown in Figure $6 A, 6 B$, aloe-emodin significantly inhibited the growth of A375 and SK-MEL-28 cells in vivo, whereas OE-beta-catenin abolished this inhibition.

\section{Discussion}

Aloe-emodin, a natural anthraquinone compound extracted from aloe, has been reported as effective agent in the treatment of a variety of cancers due to its inhibition of proliferation, migration, and invasion, and induction of cell apoptosis $(18,19)$. It has been demonstrated that aloeemodin can inhibit the migration and invasion of human tongue cancer SCC-4 cells by reducing the expression level of matrix metalloproteinase-9 (MMP-9), which has a vital role in regulating migration and metastasis in numerous human cancers (18). For human oral cancer, aloe-emodin can dose-dependently inhibit the viability of cancer cells by inducing G2/M phase arrest and enhancing the activity of alkaline phosphate (ALP) (20). In addition, aloe-emodin can enhance the radiation effects by inducing $\mathrm{G} 2 / \mathrm{M}$ 

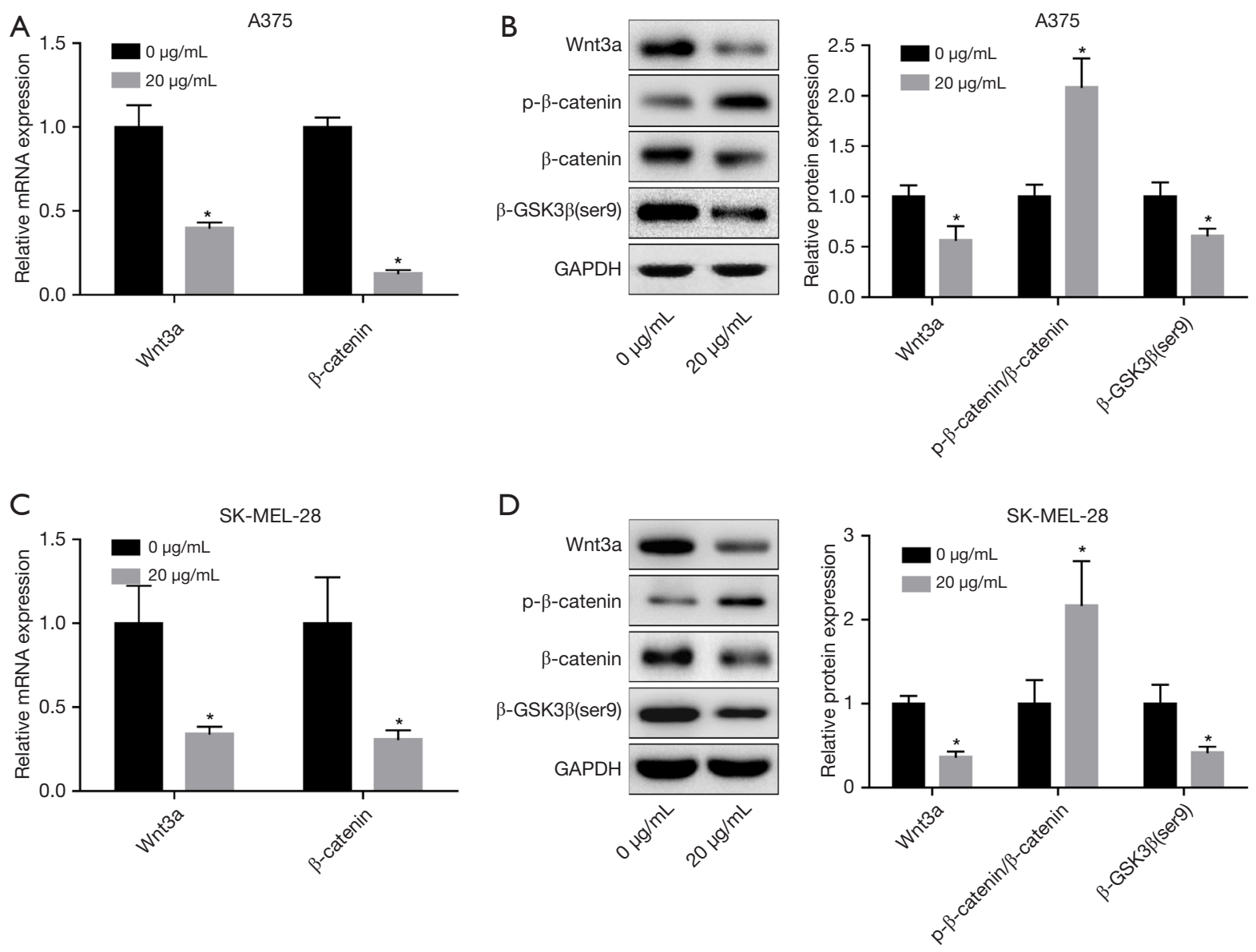

Figure 4 Aloe-emodin treatment induced the inhibition of the Wnt/beta-catenin signaling pathway. (A) qRT-PCR showed down-regulation of Wnt3a and beta-catenin in A375 cells after treatment with aloe-emodin; (B) Western blot showed the down-regulation of Wnt3a, the upregulation of p-beta-catenin/beta-catenin, and the down-regulation of p-GSK3-beta in A375 cells after treatment with aloe-emodin; (C) qRT-PCR showed down-regulation of Wnt3a and beta-catenin in SK-MEL-28 cells after treatment with aloe-emodin; (D) Western blot showed the down-regulation of Wnt3a, the up-regulation of p-beta-catenin/beta-catenin, and the down-regulation of p-GSK3-beta in SKMEL-28 cells after treatment with aloe-emodin. *, $\mathrm{P}<0.05$. qRT-PCR, reverse real-time quantitative PCR.

and S phase arrest via activation of ALP (21). In our study, it was demonstrated that aloe-emodin could inhibit the cell viability of melanoma cells in dose-dependent manner. Additionally, treatment with aloe-emodin might significantly inhibit cell proliferation, migration, invasion, G2/M phase arrest, and promote apoptosis in vitro. A nudemouse transplanted tumor model was used to detect the effect of aloe-emodin on the development of melanoma, and it was showed that aloe-emodin treatment might significantly inhibit the tumor growth of melanoma.

The Wnt signaling pathway plays critical roles in numerous fundamental processes that are essential for the development of organs in the embryonic stage and maintenance of tissues homeostasis in adults (22). However, emerging evidence demonstrates that the $\mathrm{Wnt} /$ beta-catenin signaling pathway plays a vital role in tumorigenesis in various cancers, including breast, lung, and ovarian cancers (23-26). The activation of Wnt can release beta-catenin and enter the nucleus to play a role in transcription regulation, thereby regulating cell proliferation, apoptosis, and other biological behaviors (23-26). The inhibitory function of the $\mathrm{Wnt} /$ beta-catenin signaling pathway on proliferation and the induction of apoptosis in melanoma cells has also been reported (27). Vitamin D-vitamin D receptor signal can regulate the immune level by regulating $\mathrm{Wnt} /$ betacatenin signaling, thereby improving the therapeutic effect 


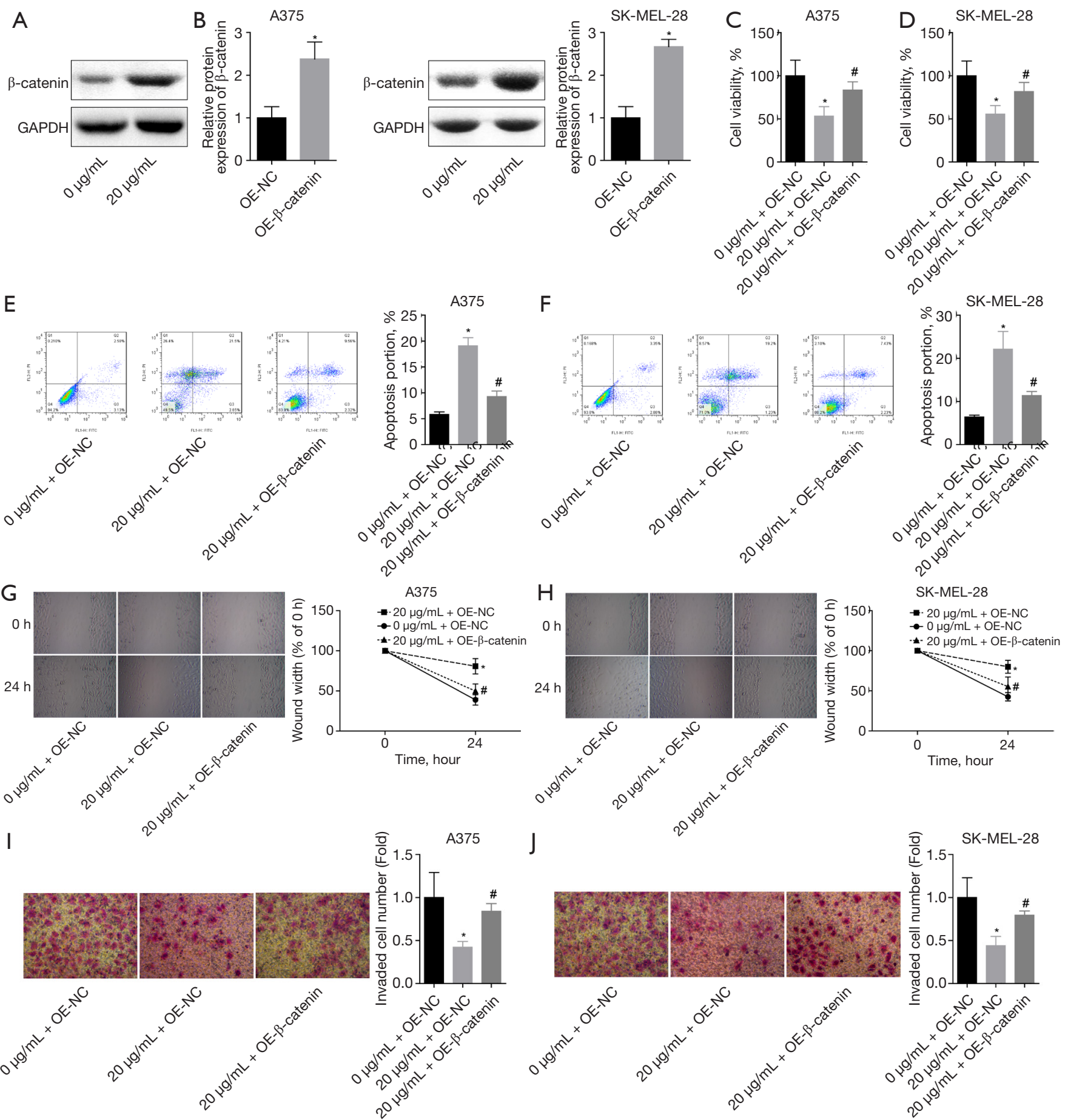

Figure 5 Aloe-emodin inhibited the migration and invasion of A375 and SK-MEK-28 cells via the Wnt/beta-catenin signaling pathway. (A,B) Western blot showed overexpression efficiency of beta-catenin in A375 and SK-MEL-28 cells; (C,D) cell viability of A375 and SK-MEL-28 cells treated with aloe-emodin and OE-beta-catenin; (E,F) flow cytometry were performed to detect apoptosis of A375 and SK-MEL-28 cells after treatment with aloe-emodin and OE-beta-catenin; $(\mathrm{G}, \mathrm{H})$ cell migration and the quantification of the distance of migration of A375 and SK-MEL-28 cells after treatment with aloe-emodin and OE-beta-catenin; (I,J) the invasion of A375 and SK-MEL-28 cells was detected after treatment with aloe-emodin and OE-beta-catenin, crystal violet was used for cell staining $(\times 400)$. *, $\mathrm{P}<0.05,20 \mu \mathrm{g} / \mathrm{mL}$ + OE-NC group vs. $0 \mu \mathrm{g} / \mathrm{mL}+\mathrm{OE}-\mathrm{NC}$ group; $, \mathrm{P}<0.05,20 \mu \mathrm{g} / \mathrm{mL}+$ OE-beta-catenin group vs. $20 \mu \mathrm{g} / \mathrm{mL}+\mathrm{OE}-\mathrm{NC}$ group. OE-NC, overexpression-negative control. 

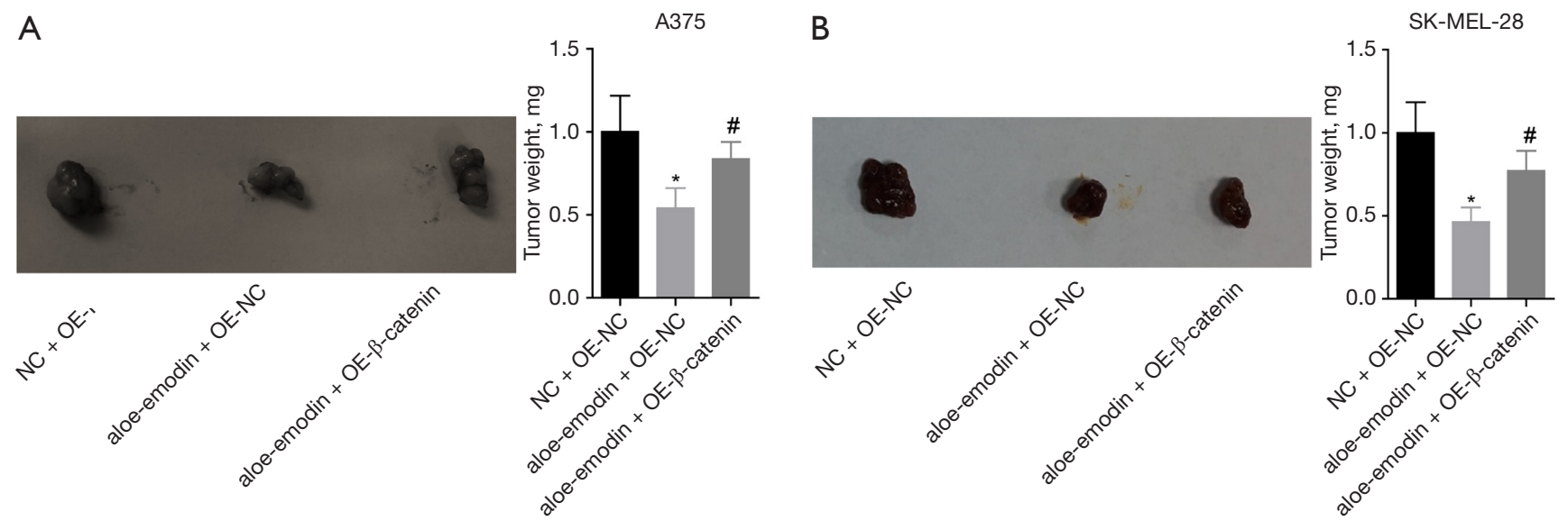

Figure 6 Aloe-emodin inhibited tumor growth via inactivation of the Wnt/beta-catenin signaling pathway in vivo. (A) The weight of the tumors were detected; (B) the weight of the tumors were detected. *, $\mathrm{P}<0.05,20 \mu \mathrm{g} / \mathrm{mL}+\mathrm{OE}-\mathrm{NC}$ group $v s .0 \mu \mathrm{g} / \mathrm{mL}+\mathrm{OE}-\mathrm{NC}$ group; , $\mathrm{P}<0.0520 \mu \mathrm{g} / \mathrm{mL}+$ OE-beta-catenin group $v s .20 \mu \mathrm{g} / \mathrm{mL}+$ OE-NC group. OE-NC, overexpression-negative control.

of immunotherapy on melanoma (28). The Wnt/betacatenin pathway may be involved in the development of melanoma by regulating immune escape (29). In addition, it has been shown that the beta-catenin inhibitor, PKF115584 , increases cell adhesion and reduces the cell migration ability in a chick embryonic neural crest environment (30). Consistently, in our study, we found that the treatment of A375 cells and SK-MEL-28 cells with aloe-emodin significantly inhibited the expression levels of Wnt3a and p-GSK3 beta, and promoted beta-catenin phosphorylation (beta-catenin was phosphorylated and degraded in the cytoplasm). Overexpression of beta-catenin abolished the aloe-emodin-induced inhibition of proliferation and enhancement of cell apoptosis.

It is well known that melanoma is a highly aggressive tumor, and metastasis is a difficult problem in the treatment of melanoma (31). It has been demonstrated that EMT is responsible for the metastasis of cancers via disruption of the intracellular junction and acceleration of cell morbidity (32). Down-regulation of E-cadherin and up-regulation of $\mathrm{N}$-cadherin and Vimentin were considered to represent the occurrence of EMT (33). In our study, we identified that treatment of A375 and SK-MEL-28 markedly up-regulated the expression level of E-cadherin and down-regulated the expression level of Vimentin. Aberrant activation of the Wnt/beta-catenin signaling pathway contributed to the EMT of tumor cells (34). Previous studies have indicated that activation of the $\mathrm{Wnt} /$ beta-catenin signaling pathway significantly enhances the Vimentin expression level (35). In this study, we found that the over-expression of beta- catenin abolished the inhibition of migration and invasion of A375 and SK-MEL-28 cells. The experimental results also showed that aloe-emodin significantly inhibited the growth of A375 and SK-MEL-28 in vivo, while OE-betacatenin abrogated this inhibition.

The present study had some limitations that should be noted. Firstly, although our results confirmed that the inhibitory effect of aloe-emodin on melanoma in vivo was inseparable from beta-catenin, there were still some errors due to the small number of animals in each group. In addition, there are also differences between nude mice and humans. The effectiveness and safety of aloe-emodin in inhibiting melanoma are worthy of analysis in humans.

\section{Conclusions}

In the present study, we demonstrated that aloe-emodin could inhibit the proliferation, migration, and invasion of A375 and SK-MEL-28 cells in vitro and in vivo by inhibiting the $\mathrm{Wnt} /$ beta-catenin pathway. Our finding indicated that aloe-emodin is a potential drug treatment for melanoma.

\section{Acknowledgments}

Funding: None.

\section{Footnote}

Reporting Checklist: The authors have completed the ARRIVE reporting checklist. Available at https://dx.doi. 
org/10.21037/atm-21-5437

Data Sharing Statement: Available at https://dx.doi. org/10.21037/atm-21-5437

Conflicts of Interest: All authors have completed the ICMJE uniform disclosure form (available at https://dx.doi. org/10.21037/atm-21-5437). The authors have no conflicts of interest to declare.

Ethical Statement: The authors are accountable for all aspects of the work in ensuring that questions related to the accuracy or integrity of any part of the work are appropriately investigated and resolved. All animal experiments were granted by the ethical committee of Huazhong University of Science and Technology (WH201904068), in compliance with Guide for the Care and Use of Laboratory Animals, 8th edition for the care and use of animals.

Open Access Statement: This is an Open Access article distributed in accordance with the Creative Commons Attribution-NonCommercial-NoDerivs 4.0 International License (CC BY-NC-ND 4.0), which permits the noncommercial replication and distribution of the article with the strict proviso that no changes or edits are made and the original work is properly cited (including links to both the formal publication through the relevant DOI and the license). See: https://creativecommons.org/licenses/by-nc-nd/4.0/.

\section{References}

1. MacKie RM, Hauschild A, Eggermont AM. Epidemiology of invasive cutaneous melanoma. Ann Oncol 2009;20 Suppl 6:vi1-7.

2. Schadendorf D, van Akkooi ACJ, Berking C, et al. Melanoma. Lancet 2018;392:971-84. Erratum in: Lancet 2019;393:746.

3. Echevarría-Vargas IM, Reyes-Uribe PI, Guterres AN, et al. Co-targeting BET and MEK as salvage therapy for MAPK and checkpoint inhibitor-resistant melanoma. EMBO Mol Med 2018;10:e8446.

4. Li J, Zhao R, Guo Y, Fang R. EMG1 interacts with NOP14 to regulate the growth, migration, and invasion of melanoma cells via the $\mathrm{Wnt} / \beta$-catenin pathway. Transl Cancer Res 2020;9:3669-79.

5. James RG, Bosch KA, Kulikauskas RM, et al. Protein kinase PKN1 represses $W n t / \beta$-catenin signaling in human melanoma cells. J Biol Chem 2013;288:34658-70.
6. Xue G, Romano E, Massi D, et al. Wnt/ $\beta$-catenin signaling in melanoma: Preclinical rationale and novel therapeutic insights. Cancer Treat Rev 2016;49:1-12.

7. Lin Y, Wang F, Xing Q, et al. The biological effect and mechanism of the $\mathrm{Wnt} / \beta$-catenin signaling pathway on malignant melanoma A375 cells. Exp Ther Med 2018;16:2032-7.

8. Kaur A, Webster MR, Weeraratna AT. In the Wnt-er of life: Wnt signalling in melanoma and ageing. Br J Cancer 2016;115:1273-9.

9. Shi L, Huo JW, Chen SS, et al. MicroRNA-22 targets FMNL2 to inhibit melanoma progression via the regulation of the $\mathrm{Wnt} / \beta$-catenin signaling pathway and epithelial-mesenchymal transition. Eur Rev Med Pharmacol Sci 2019;23:5332-42.

10. Liang G, Liu M, Wang Q, et al. Itraconazole exerts its anti-melanoma effect by suppressing Hedgehog, Wnt, and $\mathrm{PI} 3 \mathrm{~K} / \mathrm{mTOR}$ signaling pathways. Oncotarget 2017;8:28510-25.

11. Bhat G, Kudva P, Dodwad V. Aloe vera: Nature's soothing healer to periodontal disease. J Indian Soc Periodontol 2011;15:205-9.

12. Choi S, Chung MH. A review on the relationship between Aloe vera components and their biologic effects. Seminars in Integrative Medicine 2003;1:53-62.

13. Sanders B, Ray AM, Goldberg S, et al. Anti-cancer effects of aloe-emodin: a systematic review. J Clin Transl Res 2018;3:283-96.

14. Gao R, Wu X, Huang Z, et al. Anti-tumor effect of aloeemodin on cervical cancer cells was associated with human papillomavirus E6/E7 and glucose metabolism. Onco Targets Ther 2019;12:3713-21.

15. Jeon W, Jeon YK, Nam MJ. Apoptosis by aloe-emodin is mediated through down-regulation of calpain-2 and ubiquitin-protein ligase E3A in human hepatoma Huh-7 cells. Cell Biol Int 2012;36:163-7.

16. Tabolacci C, Cordella M, Turcano L, et al. Aloe-emodin exerts a potent anticancer and immunomodulatory activity on BRAF-mutated human melanoma cells. Eur J Pharmacol 2015;762:283-92.

17. Tabolacci C, Lentini A, Mattioli P, et al. Antitumor properties of aloe-emodin and induction of transglutaminase 2 activity in B16-F10 melanoma cells. Life Sci 2010;87:316-24.

18. Chen YY, Chiang SY, Lin JG, et al. Emodin, aloe-emodin and rhein inhibit migration and invasion in human tongue cancer SCC-4 cells through the inhibition of gene expression of matrix metalloproteinase-9. Int J Oncol 
2010;36:1113-20.

19. Lin JG, Chen GW, Li TM, et al. Aloe-emodin induces apoptosis in T24 human bladder cancer cells through the p53 dependent apoptotic pathway. J Urol 2006;175:343-7.

20. Xiao B, Guo J, Liu D, et al. Aloe-emodin induces in vitro G2/M arrest and alkaline phosphatase activation in human oral cancer KB cells. Oral Oncol 2007;43:905-10.

21. Luo J, Yuan Y, Chang P, et al. Combination of aloeemodin with radiation enhances radiation effects and improves differentiation in human cervical cancer cells. Mol Med Rep 2014;10:731-6.

22. Duchartre Y, Kim YM, Kahn M. The Wnt signaling pathway in cancer. Crit Rev Oncol Hematol 2016;99:141-9.

23. Krishnamurthy N, Kurzrock R. Targeting the Wnt/ beta-catenin pathway in cancer: Update on effectors and inhibitors. Cancer Treat Rev 2018;62:50-60.

24. Khramtsov AI, Khramtsova GF, Tretiakova M, et al. Wnt/ beta-catenin pathway activation is enriched in basal-like breast cancers and predicts poor outcome. Am J Pathol 2010;176:2911-20.

25. Teng Y, Wang X, Wang Y, et al. Wnt/beta-catenin signaling regulates cancer stem cells in lung cancer A549 cells. Biochem Biophys Res Commun 2010;392:373-9.

26. Nagaraj AB, Joseph $P$, Kovalenko O, et al. Critical role of $\mathrm{Wnt} / \beta$-catenin signaling in driving epithelial ovarian cancer platinum resistance. Oncotarget 2015;6:23720-34.

27. Li XJ, Li ZF, Xu YY, et al. microRNA-374 inhibits proliferation and promotes apoptosis of mouse melanoma cells by inactivating the Wnt signalling pathway through its effect on tyrosinase. J Cell Mol Med 2019;23:4991-5005.

28. Muralidhar S, Filia A, Nsengimana J, et al. Vitamin D-VDR signaling inhibits Wnt/ $\beta$-catenin-mediated melanoma progression and promotes antitumor immunity. Cancer Res 2019;79:5986-98.

29. Spranger S, Bao R, Gajewski TF. Melanoma-intrinsic $\beta$-catenin signalling prevents anti-tumour immunity. Nature 2015;523:231-5.

30. Sinnberg T, Levesque MP, Krochmann J, et al. Wntsignaling enhances neural crest migration of melanoma cells and induces an invasive phenotype. Mol Cancer 2018;17:59.

31. Ali Z, Yousaf N, Larkin J. Melanoma epidemiology, biology and prognosis. EJC Suppl 2013;11:81-91.

32. Nieto MA. Epithelial plasticity: a common theme in embryonic and cancer cells. Science 2013;342:1234850.

33. Liao TT, Yang MH. Revisiting epithelial-mesenchymal transition in cancer metastasis: the connection between epithelial plasticity and stemness. Mol Oncol 2017;11:792-804.

34. Iwai S, Yonekawa A, Harada C, et al. Involvement of the Wnt- $\beta$-catenin pathway in invasion and migration of oral squamous carcinoma cells. Int J Oncol 2010;37:1095-103.

35. Sabbah M, Emami S, Redeuilh G, et al. Molecular signature and therapeutic perspective of the epithelial-tomesenchymal transitions in epithelial cancers. Drug Resist Updat 2008;11:123-51.

(English Language Editor: A. Kassem)
Cite this article as: $\mathrm{Du} M$, Shen $\mathrm{P}$, Tan $\mathrm{R}, \mathrm{Wu} \mathrm{D}, \mathrm{Tu}$ S. Aloeemodin inhibits the proliferation, migration, and invasion of melanoma cells via inactivation of the Wnt/beta-catenin signaling pathway. Ann Transl Med 2021;9(23):1722. doi: 10.21037/atm-21-5437 